\title{
A CHANGING PATTERN OF CANCER-RELATED MORTALITY IN BASRAH
}

\section{Omran S Habib ${ }^{*}$ \& Kareem A Al-Imara ${ }^{@}$}

*PhD, Professor of Epidemiology and Health Care, Department of Family and Community Medicine, College of Medicine, University of Basrah. ${ }^{\circledR}$ Diploma in Community Medicine, Cancer Control Centre, Basrah, IRAQ.

\begin{abstract}
Cancer is a growing health problem with substantial mortality. A high mortality reflects high incidence, late detection and inadequate management.

The objective of this study is to examine the time changes of mortality rate of cancer in Basrah. The results presented in this article are all based on officially registered cancer deaths in Basrah Governorate on selected years.

Cancer of lung and bronchus, breast cancer, CNS tumors, all types of leukemia, secondaries of unknown primary site, urinary bladder cancer, stomach cancer, cancer of pancreas and cancer of liver and biliary system were the leading causes of cancer related death and accounted for $68.7 \%$. The time trend showed some tendency for mortality rates to increase over years for most cancers except a noticeable decline in recent years.

In conclusion, cancer is a major cause of death in Basrah accounting for nearly $10 \%$ of all officially registered deaths. An initial modest increase followed by some tendency to decrease in mortality rate is noticed. Further comprehensive studies are highly recommended.
\end{abstract}

\section{Introduction}

Pancer represents an important and growing health problem ${ }^{1,2}$. The risk in general is higher in developed countries compared to developing countries. The cause-specific mortality rate associated with cancer, however, is higher in developing countries mainly due to inadequate management ${ }^{3}$. In Basrah governorate extensive efforts were made to quantify the risk and mortality of cancer over the last decades and evidence from published work indicates modest increase in incidence rates of most cancers and relatively high mortality ${ }^{4-8}$. A significant question is always asked; Did cancer increase in Basrah over years? The answer to this question remained inconclusive despite some evidence on a modest rising risk. In this paper we attempt to examine the change in cancer risk over years through the examination of mortality rates as a proxy measure of incidence rate. The main justification behind the use of mortality data is the fact that death certification is obligatory in Iraq. Death certificates contain important section on the cause of death. The ascertainment of death event is definite but the documentation of cause of death leaves some doubt on its accuracy. Cancer as a cause of death is likely to be better documented as it is visible disease both to doctors and to the public. The present article was prepared to examine the time changes of mortality rate of cancer in Basrah.

\section{Methods}

The data used in this article were all obtained with kind permission from Basrah Cancer Research Group (BCRG) data base and from statistical sections in Basrah Directorate General of Health Services. Mortality data used in this article are routine data-based retrospectively compiled covering all 
deaths due to cancer registered in Basrah governorate during points in time; 1989, 1997, 2005 and 2008-2013 supplemented by additional numbers for the years 20142016.

For the years 1989, 1997 and 2005, all paper-based death registries were examined in details to identify any death for which one type of cancer was written as the cause of death. The offices of death registration keep an inventory on all deaths registered in Basrah. Seven death registries were visited. These were the registries in Basrah city, Hartha, Qurna, Mdainah, Zubair, Abul-Khasib and Shatt $\mathrm{Al}$ Arab. The choice of the three years for the purpose of study was approximately eight years apart. These were 1989 as an example of stable status in Basrah one year after the cessation of the Iraq-Iran War, 1997 which represents the last of the worst years of economic sanctions on Iraq before the adoption of the understanding memorandum (Oil for Food) between Iraq and United Nations and the 2005 as a point in time 8 years after 1997. For each year, the total numbers of deaths due to cancer were compiled.

For the years 2008-2013, a request was submitted to the Research Committee at the Directorate General of Health Services in Basrah to facilitate the acquisition of mortality related data available with the Statistical Sections of the Directorate.

An electronic file was available for the years 2008-2013 and was supplied to the researchers. For improving the time span of time trend, further extension of data was made by requesting statistics on cancer related deaths for the years 20142016 from the Cancer Control Centre in Basrah.

In all these sources it was possible to compile data on age at the time of death, sex, date of death, place of residence, cause of death and type of cancer.

Data on Basrah population were based on figures available with the BCRG. These figures were built on various sources including the Ministry of Planning and Developmental Cooperation-Central Office for Statistics ${ }^{9}$, The Ministry of Health $^{10}$ and figures estimated by Basrah Cancer Research Group using extrapolation from 1997 population census.

\section{Results}

\section{The leading cancer-related causes of death (2008-2013)}

Table I indicates that $68.9 \%$ of all cancer related mortality in Basrah governorate are attribute to ten types of cancers. These are cancer of lung and bronchus, breast cancer, CNS tumors, all types of leukemias, secondaries of unknown primary site, urinary bladder cancer, stomach cancer, cancer of pancreas and cancer of liver and biliary system. Other causes are detailed in Table I.

\section{Time trend}

Looking closely at the pattern of cancer specific mortality rates Figure 1 and Table II it is possible to identify the following patterns:

First; it seems that cancer specific mortality rate was increasing in Basrah over the last three decades with some tendency to decline in recent years.

Second; malignant diseases with evidence of rising mortality (Figure 2) include those of blood, breast, CNS, lymphomas, Bones, liver, Colon-rectum, uterus-cervix and kidney.

Three; other cancers show either a tendency to declining mortality rate (lymphomas) or inconclusive trend in the remaining cancers. 
Table I: Causes of death attributed to malignancy in Basrah during 2008-2013

\begin{tabular}{|c|c|c|c|c|}
\hline Cause & ICD Code $^{@}$ & Number & $\%$ & $\begin{array}{c}\text { MR per } \\
100000 \\
\text { population }\end{array}$ \\
\hline Lung and bronchus & C34 & 752 & 13.2 & 4.82 \\
\hline Breast & $\mathrm{C} 50$ & 606 & 10.6 & 3.89 \\
\hline Brain and spinal cord & C70-72 & 543 & 9.5 & 3.48 \\
\hline All types of leukemia & C91-94 & 460 & 8.0 & 2.95 \\
\hline Secondaries of unknown primary & C76-80 & 370 & 6.5 & 2.37 \\
\hline Urinary bladder & C67 & 336 & 5.9 & 2.15 \\
\hline Stomach & $\mathrm{C} 16$ & 319 & 5.6 & 2.05 \\
\hline Pancreas & $\mathrm{C} 25$ & 289 & 5.1 & 1.85 \\
\hline Liver and biliary system & C22-23 & 250 & 4.4 & 1.60 \\
\hline All other blood disorders & C95-96 & 247 & 4.3 & 1.58 \\
\hline Colon-Rectum & C18-20 & 237 & 4.2 & 1.52 \\
\hline Bones & C40-41 & 179 & 3.1 & 1.15 \\
\hline Uterus-Cervix & C53-55 & 136 & 2.4 & 0.87 \\
\hline Prostate & C61 & 104 & 1.8 & 0.67 \\
\hline Ovary & C56 & 94 & 1.6 & 0.60 \\
\hline Kidney/ureter & C64-66 & 94 & 1.6 & 0.60 \\
\hline Oral cavity & $\mathrm{C} 00-14$ & 72 & 1.3 & 0.46 \\
\hline Endocrine & C73-75 & 66 & 1.2 & 0.42 \\
\hline Small intestine & & 66 & 1.2 & 0.42 \\
\hline Other GIT sites & & 66 & 1.2 & 0.42 \\
\hline Lymphomas (HD, NHL and others) & C81-85 & 61 & 1.1 & 0.39 \\
\hline Esophagus & & 59 & 1.0 & 0.38 \\
\hline Soft tissue & C45-49 & 50 & 0.9 & 0.32 \\
\hline Skin & C43-44 & 36 & 0.6 & 0.23 \\
\hline Eye & C69 & 17 & 0.3 & 0.11 \\
\hline All other sites & --- & 210 & 3.7 & 1.35 \\
\hline Total & -- & 5719 & 100.0 & 36.68 \\
\hline
\end{tabular}

*Mid-period population for the years 2008-2013=2598 856

${ }^{\circledR}$ ICD: International classification of Disease

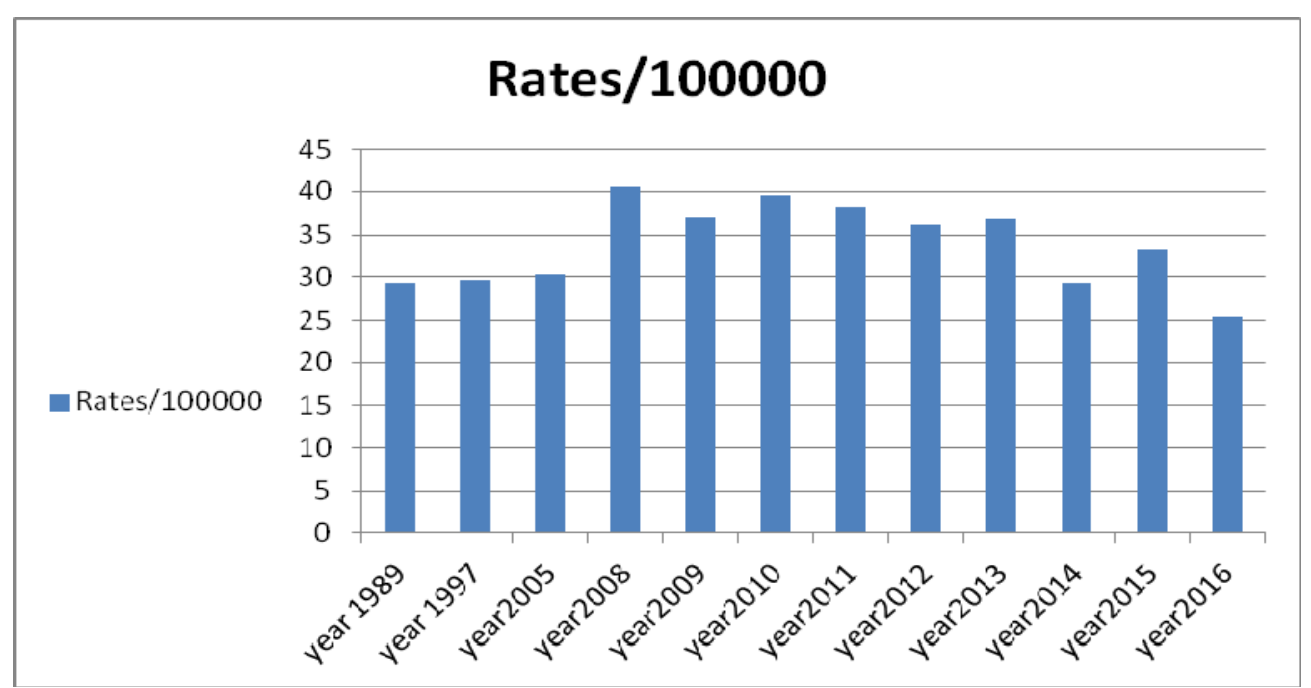

Figure 1: Time trend of cancer related mortality: Basrah 1989-2016 
Table II: Comparison of annual mortality rates/100000 of all cancer deaths in Basrah for the years 1989, 1997, 2005 and the average for 2008-2016.

\begin{tabular}{|l|c|c|c|c|}
\hline \multicolumn{1}{|c|}{ Type of cancer } & $\mathbf{1 9 8 9}$ & $\mathbf{1 9 9 7}$ & $\mathbf{2 0 0 5}$ & $\mathbf{2 0 0 8 - 2 0 1 6}$ \\
\hline Lung and bronchus & 5.1 & 5.1 & 4.3 & 5.1 \\
\hline Urinary Bladder & 3.5 & 3.3 & 2.8 & 2.2 \\
\hline Blood/leukaemias & 2.2 & 3.4 & 2.7 & 4.7 \\
\hline Breast & 3.3 & 1.6 & 3.2 & 4.1 \\
\hline Lymphomas & 1.9 & 2.7 & 2.1 & 2.4 \\
\hline CNS & 1.4 & 2.0 & 2.0 & 3.6 \\
\hline Stomach & 1.6 & 2.2 & 1.1 & 2.1 \\
\hline Pancreas & 1.4 & 1.5 & 1.2 & 1.9 \\
\hline Bones & 0.8 & 1.5 & 1.0 & 1.2 \\
\hline Liver & 1.0 & 1.0 & 1.3 & 1.7 \\
\hline Colon- Rectum & 0.6 & 1.1 & 1.3 & 1.6 \\
\hline Uterus & 0.6 & 1.0 & 0.8 & 0.9 \\
\hline Secondary & 1.1 & 1.0 & 0.6 & 2.5 \\
\hline Prostate & 0.6 & 1.0 & 0.6 & 0.7 \\
\hline Ovary & 0.5 & 0.7 & 0.5 & 0.6 \\
\hline Oesophagus & 0.5 & 0.7 & 0.4 & 0.4 \\
\hline Kidney & 0.4 & 0.2 & 0.6 & 0.6 \\
\hline Skin & 0.1 & 0.3 & 0.5 & 0.3 \\
\hline All Others & 2.1 & 1.5 & 2.1 & 3.3 \\
\hline Total & 29.2 & 33.3 & 32.3 & 38.1 \\
\hline
\end{tabular}

Mid period population for the years 2008-2016 $=2602893$

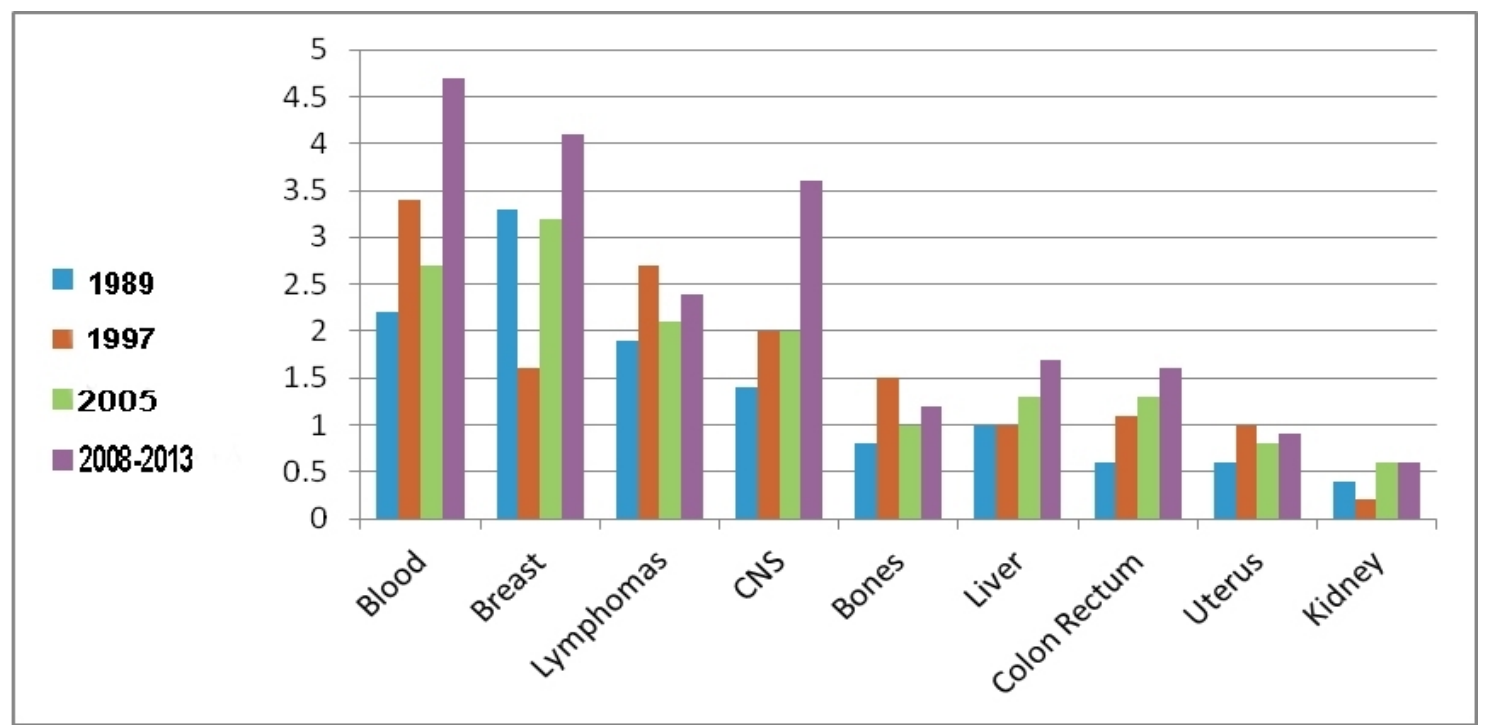

Figure 2: Cancers which showed clear increase in mortality rate with time 


\section{Discussion}

Medical and legal bodies or personnel usually ascertain the fact of death. In countries where burial of dead persons requires officially issued death certificates, death registries can be reliable regarding the total numbers of death during a specified period of time ${ }^{11}$. Incompleteness in death registries may arise early in life when neonates may be born and die without being registered as births or deaths. This is expected to be very marginal in Iraq and in Basrah for three reasons. The first is that Islamic rule requires that each dead person regardless of age should be buried. The second is the socioeconomic development in the country and the wide spread education which enhance the documentation of vital events. And the third is the legal requirement for any event of death to be documented. With respect to cause of death, some degree of inaccuracy is likely ${ }^{11}$. People with cancer may have died because of other reasons complicating cancer itself or unrelated to it. In other instances as in the elderly for example cancer may be the cause of death but the ascertainment of cause of death is amenable to errors. It is not uncommon to find "senility" written as the cause of death in such very old people. In such age group, the incidence of cancer is usually high. This may mean that some cancer deaths are lost and the overall risk of death is underestimated. The investigators did their best to review carefully the death registries in Basrah. The data source used in the view of the investigators is reliable. The figures are very close to the official figures issued by the health authorities on deaths in Basrah $^{12}$. It remains a possibility however, that some errors do exist and one should admit that scientific research results are not always perfect.

Cancer risk and cancer mortality in any population are two indicators that could reflect cumulative effect of environmentally related exposure to carcinogens and effectiveness of preventive and therapeutic health care. The effect of genetics and exposure to carcinogens prior to birth and even prior to conception cannot be excluded since a substantial amount of cancer deaths occur very early in life. This is true in Basrah and elsewhere as demonstrated in this paper.

The leading cancers as causes of death are not very much different from those reported in other parts of the world ${ }^{1,2}$. Some of these cancers are related to avoidable risk factors. Lung cancer for example is the prime cause of deaths related to cancer in Basrah. Most of lung cancer is related to cigarette smoking; a habit which can be avoided from the start or stopped among those who used to it. The distribution of cancer deaths though showed some significant variation with time it is difficult to explain such variation. However, the observed differences in the distribution with time cannot be considered as evidence of true change unless the reference population is taken into consideration in each of the studied years. A population-based death registration is available in Basrah. Thus the pattern with time is likely to reflect both changes in risk factor and incidence of cancer and in the effectiveness of health care services. The decline in the recent years as shown in Figure 1 could be an evidence for availability of better patient care.

Evidence from the results in this paper and previous studies ${ }^{6-8}$ suggests some degree of rise in the risk of most cancers in Basrah. The cancer specific mortality rates in different years do support these findings. Only small proportion of cancer types showed no change over time. The increase in mortality rates over time is however, modest. Lack of tangible increase in cancer specific mortality rates might be due to better survival among cancer cases during the last decade or so. More facilities for diagnosis and 
treatment became available in Basrah (though not adequate at all). In addition, some screening programs were initiated. These could have contributed to earlier diagnosis, more effective treatment and better outcome. This is supported by the fact that in recent years a decline is noticed in mortality rates as shown in Figure 1. This decline, in view of authors is likely to be true but causes related to inadequate ascertainment of cause of death and inadequate registration cannot be excluded at this stage of the study.

Regardless, cancer is a real health problem in Basrah. It is a significant contributor to the toll of death and a major consumer of resources. Continuing research on cancer is vital but need support from various interested partners. Conclusion: Cancer is a major cause of death in Basrah accounting for nearly $10 \%$ of all officially registered deaths. An initial modest increase followed by some tendency to decrease in mortality rate is noticed. Further comprehensive studies are highly recommended.

Acknowledgement: The authors would like to thank Assistant Professor Dr. Asaad Al-Yassen, Department of Family and Community Medicine, for his useful comments on the article draft, and the Statistical Section at the Directorate General for Health Services for their generous help in providing the data used in this study.

\section{References}

1. Mathers C, Fat DM, Boerma JT. The global burden of disease: 2004 update. World Health Organization, Geneva 2008

2. Ferlay J, Soerjomataram I, Ervik M, Dikshit R, Eser S, Mathers C et al. GLOBOCAN 2012, Cancer Incidence and Mortality Worldwide: IARC, Lyon, France: International Agency for Research on Cancer; 2013. Available from: http://globocan.iarc.fr.

3. Edwards BK, Brown ML, Wingo PA, Howe HI, Ward E, Reis LAG. Annual report to the nation on the status of cancer, 1975-2002. Featuring population-based trends in cancer treatment. J Natl Cancer Inst 2005; 97(19):1407-1427.

4. Habib OS, Al-Ali JK. Cancer in Basrah 2005-2011: Characteristics of person, place and time. A confidential Report submitted to the Iraqi Cancer Board 2011.

5. BCRG. Cancer in Basrah: epidemiological analysis of incident cancer 2005-2008. Basrah Cancer Research Group. Dar AlKutub for Press and Publication, Basrah 2010.

6. Hagopian A, Lafta R, Hassan JG, Davis S, Mirick D, Takaro T. Trends in childhood leukemia in Basrah, Iraq 1993-2007. Am J Public Health 2010; 100(6):1081-1087.

7. Habib OS. Environment and health in Southern Iraq: Facts and future prospects. Marina Mesopotamica 2005; 20: 7-19.

8. Atwan $\mathrm{AH}$, Habib OS. One-year survival of children with malignant diseases in Basrah. The Medical Journal of Basrah University 2017; 35 (1):1-10.

9. Ministry of Planning. Central Statistical Organization. Statistics of Men and Women. Iraq.2013. Available at:www.cosit.gov.iq/documents/statistics\%5Chuman\%20development\%Cfull\%20reports/man\%20and\%20Wo men\%in\%202013.pdf Accessed 15 November 2017.

10. Ministry of Health. Cancer Registry Reports for the years 2009-2013.

11. Buehler JW. Surveillance. In: Rothman KJ, Greenlan S, Lash T, eds. Modern epidemiology. Lippincott Williams and Wilkins, Philadelphia, USA 2008.

12. Al-Imara KA. Mortality in Basrah: A paper presented at the workshop on "Cancer Registration and Environmental Measurements in Basrah- Methods, Application and Analysis. Griefs wald University-Germany 2006 